\title{
PENGEMBANGAN BATAKO SISTEM INTERLOCKING UNTUK BANGUNAN TAHAN GEMPA
}

\author{
Diarto Trisnoyuwono ${ }^{1}$, Marsinta Simamora ${ }^{2}$, Priska G. Nahak ${ }^{3}$
}

\begin{abstract}
:
Earthquakes as a natural phenomenon have caused many casualties and property.for the examples human casualties from the Aceh earthquake on December $26^{\text {th }}, 2006$ more than 180 thousand people, the Nias earthquake on March 15 th, 2005 have more than 3000 of victims andlast the Yogyakarta earthquake on $27^{\text {th }}$ May 2006 over 5700 victims. Based on observations most of the human victims caused by falling by the collapsed building. One of the elements of the building that is easy to fail when an earthquake strike is part of the wall.The walls are composed of clay bricks or concrete bricks only able to withstand axial force but weak in resisting lateral force perpendicular to the plane. Innovation model of brick to overcome the problem is batako interlocking system. Batako hooks (Interlock block) is a wall building material that has a hook to lock movement due to lateral force. Interlock block is the development of the brick by adding lips on certain sides as a lock. The developed brick model with a dimensions length of $30 \mathrm{~cm}$, height of $15 \mathrm{~cm}$ and thickness of $10 \mathrm{~cm}$, which is equipped with bulge / lips on all four sides. The portion of the mixture used is 1 cement: 5 sand. The molded brick was applied to a wall-mounted pairs product with a length of $1.5 \mathrm{~m}$ and a height of $1 \mathrm{~m}$. Based on the calculation of material requirement from brick wall, it is known that the specific material for inserting an interlocking brick is 25\% less than conventional batako pairs, besides the time required to obtain a neat pair of interlocking bricks is 7.5 minutes faster when compared with Installation of conventional brick.
\end{abstract}

Keyword : Interlocking Brick, space material, duration of installing.

\section{PENDAHULUAN \\ Latar Belakang}

Di saat setelah kejadian gempa bumi yang menjadi salah satu fokus utama ketika mengamati kejadian gempa adalah korban di jiwa. Berdasarkan fakta sebagian besar korban tertimpa oleh bagian bangunan yang runtuh. Elemen suatu bangunan yang mudah mengalami kegagalan apabila terjadi gempa adalah bagian dinding. Dinding yang tersusun dari bata merah atau batako hanya mampu menahan gaya aksial tetapi lemah dalam menahan gaya lateral tegak lurus bidang. Hal tersebut cukup beralasan karena ikatan spesi antara batako hanya berfungsi sebagai perekat yang tidak cukup kuat menahan gaya horisontal, disamping itu permukaan batako yang rata juga tidak memberikan daya ikatan yang baik.

Salah satu azas utama dalam penyediaan bangunan sipil adalah untuk tujuan kemanusiaan. Hal tersebut mempunyai makna bahwa manusia harus menjadi prioritas utama yang harus dilindungi dari segala macam pembebanan bangunan. Manusia sebagai penghuninya harus dapat tinggal secara nyaman, aman dan terjangkau pembangunannya (Widodo, 2007). 
Pada prinsipnya bangunan tahan gempa harus bersifat sangat kaku. Bangunan yang kaku akan membentuk suatu bangunan yang solid, sehingga pada saat gaya-gaya dikenakan pada tiap bidang bangunan tidak terjadi perubahan bentuk yang besar.

Batako kait (Interlock block) adalah material penyusun dinding yang mempunyai pengait untuk mengunci pergerakan akibat gaya lateral. Interlock block merupakan pengembangan dari batako dengan menambahkan lips pada sisisisi tertentu sebagai pengunci.

Diharapkan dengan modifikasi bentuk batako atau bata beton dengan sistem interlock dapat mengurangi kerusakan pada dinding akibat gempa.

\section{Latar belakang Masalah}

Apakah model batako tahan gempa system interlocking dapat memberikan keuntungan dari aspek penghematan material, mengurangi kebutuhan pekerja, waktu pemasangan yang lebih cepat dan kerapihan hasil pasangan.

\section{Tujuan Penelitian}

Bertujuan untuk dapat mengembangkan model batako interlocking system yang dapat memberikan keuntungan dari aspek penghematan material spesi pasangan batako, menghemat tenaga manusia dan waktu pemasangan.

\section{Manfaat Penelitian}

Model batako tahan gempa system interlocking dapat memberikan keuntungan dari aspek penghematan material, mengurangi kebutuhan pekerja, waktu pemasangan yang lebih cepat dan kerapihan hasil pasangan.

\section{Efek gempa pada dinding batako}

Bangunan yang terbuat dari batako merupakan struktur yang rapuh dan salah satu jenis bangunan yang paling berbahaya apabila mengalami gempa. Sebagian besar korban jiwa manusia disebabkan oleh karena tertimpa runtuhnya bagian dinding bangunan. Oleh sebab itu sangat penting untuk mengetahui perilaku jenis bangunan tersebut, sehingga dapat dicarikan pemecahannya secara teknis.

Gerakan tanah yang terjadi selama gempa menyebabkan gaya inersia pada bangunan. Gaya - gaya tersebut merambat dari struktur atap, dinding sampai dengan bagian pondasi. Struktur bangunan yang aman adalah struktur yang mampu memastikan gaya - gaya tersebut dapat mencapai tanah tanpa menyebabkan kerusakan atau keruntuhan. Dari ketiga komponen bangunan dari batako (atap, dinding dan pondasi), dinding merupakan komponen yang paling berbahaya untuk mengalami keruntuhan, dimana bagian ini sangat lemah menerima gaya lateral dalam arah tegak lurus bidang, tetapi kuat menerima gaya lateral searah bidang dinding (Gambar 1. - Murty, 2003).

\section{Batako}

Bentuk umum batu bata adalah empat persegi panjang, bersudut siku, tajam dan permukaannya rata, panjang bata umumnya dua kali lebar bata, dan tebalnya tiga perempat dari lebarnya, ukuran tersebut dipilih agar bata dapat diangkat dengan satu tangan tanpa alat bantu.

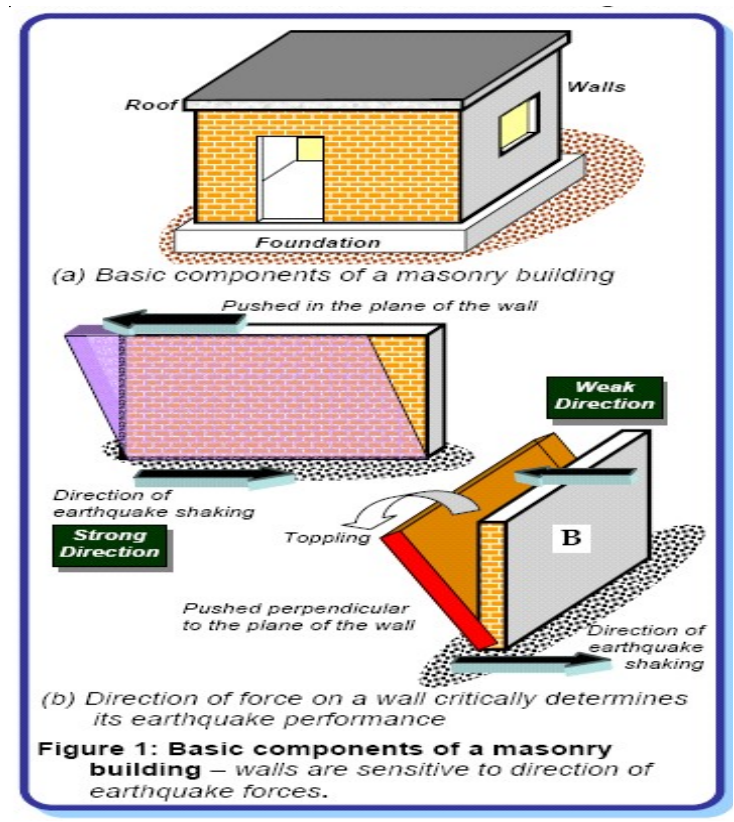

Gambar 1. Dua tipe gaya lateral yang bekerja pada dinding (Murty, 2003) 


\section{\begin{tabular}{l|l}
50 & JUTEKS Jurnal Teknik Sipil
\end{tabular}}

\section{Batako Interlocking}

Bata kait (Interlock block) adalah material penyusun dinding yang mempunyai pengait untuk mengunci pergerakan akibat gaya. Interlock block merupakan pengembangan dari batako dengan menambahkan lips pada sisi-sisi tertentu sebagai pengunci.

Interlock block telah dikembangkan dan banyak digunakan di luar negeri. Di Amerika dan Kanada dikenal beberapa jenis interlock block, diantaranya CMUs, Haener Block yang dirancang sebagai mortarless interlock block. Kemudian Verot Oaks Building Blocks, Inc. (VOBB), interlock block berbentuk segi empat berukuran enam kali enam inchi yang disusun membentuk grid.

Sementara di Indonesia walaupun masih jarang terdapat beberapa produk interlock block, diantaranya DURABLOCK dan kiblock. DURABLOCK didesain untuk menggunakan sedikit mortar, sedangkan kiblock sudah didesain sebagai material mortarless.

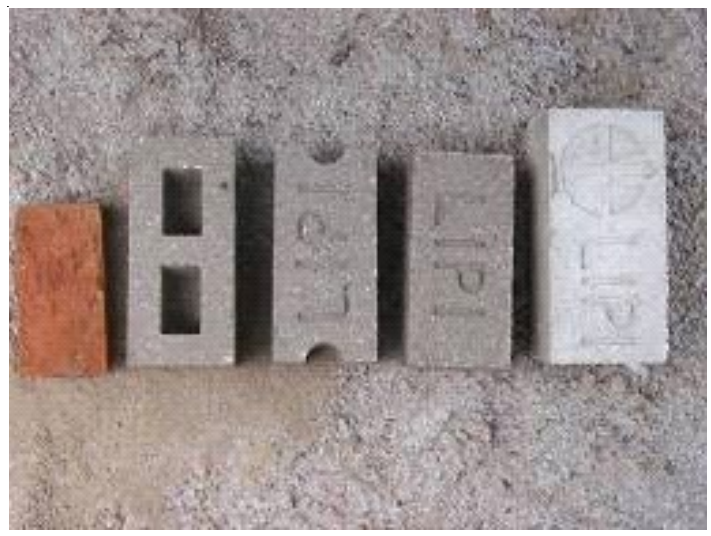

Gambar 2. Model batako tahan gempa pengembangan LIPI

\section{METODE PENELITIAN}

\section{Tahapan Pembuatan Batako Interlocking}

Urutan pelaksanaan untuk pembuatan batako adalah sebagai berikut :

1.Perancangan dan pembuatan cetakan dan alat pres batako.

2.Perancangan campuran, perbandingan volume semen dan pasir yang digunakan adalah 1 semen : 5 pasir dengan faktor air semen (fas) 0,5 .

3.Pengujian sifat fisik bahan - bahan penyusun campuran batako.

4.Pengujian sifat - sifat mekanik dan fisik campuran adonan batako.

5.Pencetakan benda uji batako.

6.Perawatan selama 28 hari, benda uji direndam dalam air.

7.Pengujian sifat mekanis dan fisik batako, meliputi kuat tekan, penyerapan air, uji jatuh, uji gores, bentuk dan struktur batako.

8.Pembuatan dinding batako build scale. Bahan dasar pembuatan batako tahan gempa dan konvensional sama yaitu dari semen, pasir dan air.

\section{Rencana Produk Batako}

Benda uji batako berukuran lebar panjang $30 \mathrm{~cm}$; lebar $10 \mathrm{~cm}$ dan tinggi $15 \mathrm{~cm}$; kedalaman tonjolan $10 \mathrm{~cm}$; kedalaman tonjolan $10 \mathrm{~cm}$. Seperti yang terlihat pada gambar berikut :

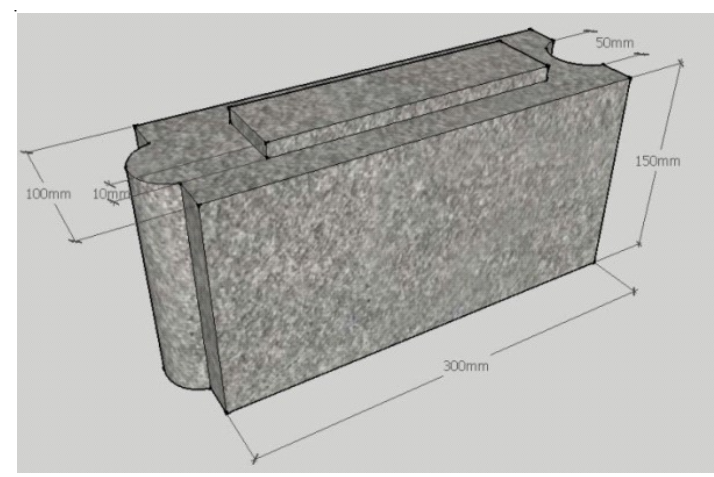

Gambar 3. Prototype Batako system interlocking

\section{Rencana Pembuatan Dinding Skala Penuh}

Produk batako tahan gempa ini nantinya dibuat produk dinding penuh untuk kebutuhan satu ruangan, dengan ukuran tinggi 1.5,0 meter dan lebar 1,5 meter x 4 sisi. Tahap awal adalah pembuatan batako tahan gempa di lokasi laboratorium struktur, kemudian benda uji batako tersebut diberi perawatan dengan cara direndam di dalam bak air selama minimal 28 hari. Setelah proses perawatan tersebut, batako 
sudah siap dipasang untuk pembuatan dinding, batako diberi spesi mortar dengan perbandingan volume semen - pasir adalah $1: 5$.

\section{Teknik Analisa}

Jenis pengamatan terhadap model batako interlocking adalah dari aspek penghematan material spesi, durasi waktu pemasangan dan kerapihan hasil pemasangan sebagai produk dinding batako hasilnya akan dibandingkan dengan produk batako konvensional.

\section{HASIL DAN PEMBAHASAN}

\section{Pembuatan cetakan batako}

Alat cetak batako yang dirancang untuk dikerjakan secara manual, yaitu campuran adonan batako dimasukkan dan selanjutnya dipadatkan dengan cara ditusuk - tusuk dan kemudian ditekan dengan bagian penutup cetakan. Alat ini dirancang untuk mencetak batako interlocking, yakni batako yang saling terhubung satu batako dengan yang lain. Proses pencetakan dikerjakan secara manual dan dapat menghasilkan batako interlock yang presisi, seragam dan padat.

Ukuran cetakan batako memiliki dimensi tinggi $15 \mathrm{~cm}$, tebal $10 \mathrm{~cm}$ dan panjang $30 \mathrm{~cm}$ dibuat dari bahan plat baja, cetakan memiliki pengunci dari baut yang bisa dilepas untuk membuka cetakan secara horizontal.

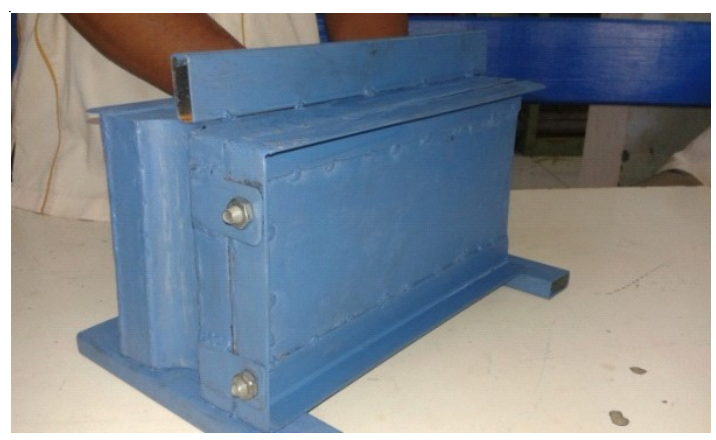

Gambar 4. Prototype Batako system interlocking

\section{Pembuatan batako interlocking}

Pembuatan batako interlocking menggunakan porsi campuran 1 bagian semen Portland dan 5 bagian pasir pasang dengan faktor air semen sebesar maksimum 0.5. Adonan dicampur dan dituang dalam cetakan yang telah dilumuri dengan oli bekas agar mudah untuk dilepaskan cetakannya nanti. Pasir yang digunakan adalah yang tergolong zona agak halus dengan tujuan agar batako memiliki tekstur permukaan yang halus.

Dalam sekali campuran adonan dibatasi pembuatan 10 buah batako secara menerus, hal ini dimaksudkan untuk menjaga konsistensi adonan dan menyediakan waktu untuk pencetakan setiap batako secara baik (padat dan rapi).

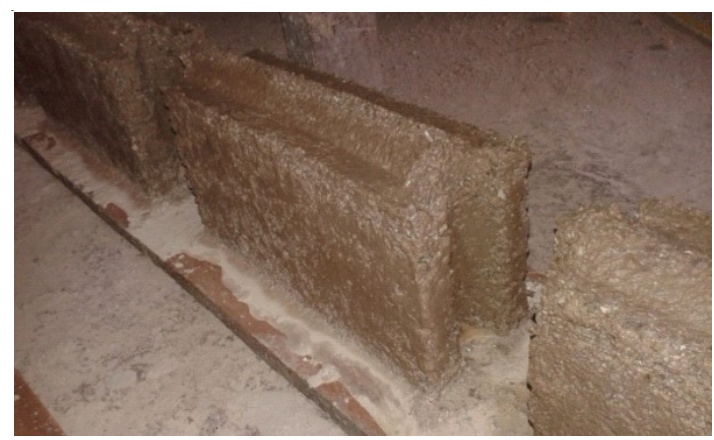

Gambar 5. Batako interlocking hasil cetakan

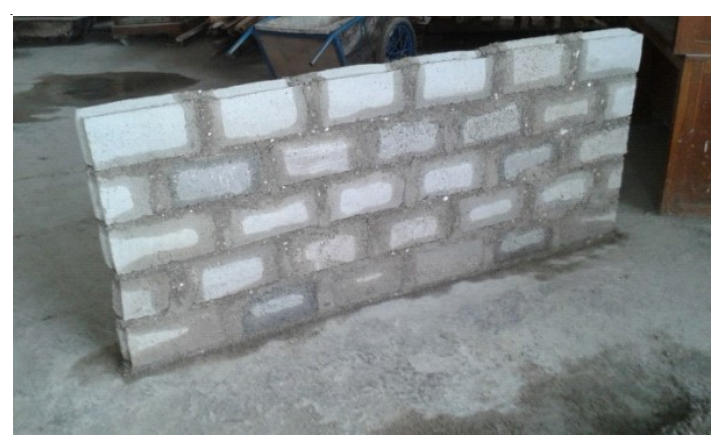

Gambar 6. Tampak susunan batako dalam formasi pasangan dinding

\section{Perhitungan Pemakaian Material Spesi Pasangan Batako}

Perhitungan pemakaian material spesi untuk pasangan dinding system interlocking yaitu berdasarkan pada seberapa luas bidang dinding yang dapat dibuat dari sekali mencampur secara 


\section{JUTEKS Jurnal Teknik Sipil Volume 2 Nomor 1 April 2017}

manual adonan mortar spesi, yang kemudian hasilnya dibandingkan dengan kebutuhan material spesi untuk membuat bidang dinding dari batako konvensional, perlu diketahui batako kovensional ini merupakan batako pres / batako semen yang berlubang. Ukuran yang digunakan juga sama dengan ukuran batako interlocking yaitu $15 \times 10 \times 30 \mathrm{~cm}$.

Berikut ini adalah perhitungan kebutuhan bahan pembuatan pasangan dinding batako :

Asumsi berat volume semen adalah $1250 \mathrm{~kg} / \mathrm{m}^{3}$ Luas dinding $=0,75 \times 1,8=1,35 \mathrm{~m}^{2}$

Volume PC $=1,36 \times 1,35=1,836 \mathrm{~kg} / 40=$ 0.0459 sak semen

Volume PP $=0,009 \times 1,35=0,01215 \mathrm{~m}^{3}$

Jadi perbandingan material untuk spesi pasangan adalah $1 \mathrm{PC}: 3$ pasir.

Kebutuhan bahan untuk pembuatan sebuah batako interlocking :

Volume $=0,3 \times 0,15 \times 0,10=0,0045 \mathrm{~m}^{3}$
Dalam sekali campuran ditargetkan dapat mencetak 10 buah batako, maka volume total batako menjadi :

$0,0045 \mathrm{~m}^{3} \times 10=0,045 \mathrm{~m}^{3}$ atau $0,045 \times 1000=$ 45 liter atau $45 \mathrm{dm}^{3}$

Jika rencana porsi campuran batako adalah 5 bagian pasir dan 1 bagian semen Portland. Maka kebutuhan bahan untuk membuat 10 (sepuluh) batako adalah sebagai berikut :

Semen : $2,50 \mathrm{~kg}=0,002 \mathrm{~m}^{3}=1$ ember cor ukuran 2 liter

Pasir pasang: $14 \mathrm{~kg}=0,01 \mathrm{~m}^{3}=5$ ember cor ukuran 2 liter

Berikut ini perbandingan kebutuhan bahan untuk pembuatan batako dan bahan spesi pasangan dinding seluas $1,35 \mathrm{~m}^{2}$ antara batako konvensional dan batako interlocking (ukurannya sama antara batako konvensional dan batako interlocking).

\begin{tabular}{|l|l|l|l|}
\hline & Bahan batako & Bahan spesi & Waktu pemasangan \\
\hline Batako konvensional & Semen $: 2,50 \mathrm{~kg}$ & Semen $: 1,836 \mathrm{~kg}$ & 17,5 menit \\
& Pasir $: 14 \mathrm{~kg}$ & Pasir $: 17 \mathrm{~kg}$ & \\
\hline Batako interlocking & Semen $: 2,50 \mathrm{~kg}$ & Semen $: 1,377 \mathrm{~kg}$ & 10,00 menit \\
& Pasir $: 14 \mathrm{~kg}$ & Pasir : $12,75 \mathrm{~kg}$ & \\
\hline
\end{tabular}

Dari tabel tersebut diperoleh hasil bahwa kebutuhan material pasangan batako untuk system interlocking lebih menghemat penggunaan bahan baku sekitar $25 \%$. Selain itu waktu yang dibutuhkan untuk memasang batako interlocking lebih cepat 7,5 menit jika dibandingkan dengan batako konvesional. Karena bentuk geometric batako interlocking memungkinkan untuk memperoleh kerapihan hasil pasangan yang lebih cepat, tanpa benang acuan batako dapat terpasang dengan rapi.Material spesi lebih tipis jika dibandingkan dengan pemasangan batako konvensional, hal ini dimungkinkan karena adanya system saling mengunci dari batako (interlocking) yang menghasilkan ikatan antar batako lebih baik / kuat.

\section{KESIMPULAN DAN SARAN}

\section{Kesimpulan}

Batako system interlocking terbukti memiliki keunggulan dari aspek penghematan material pasangan (spesi batako), keterlibatan tenaga tukang yang lebih sedikit, kecepatan pemasangan dan kerapihan pasangan dinding.

\section{Saran}

Untuk keperluan produksi massal dan hasil cetakan batako yang lebih padat dan seragam maka perlu dikembangkan alat press batako system interlocking serta penggunaan additive foaming agent agar bobot batako semakin ringan. 


\section{DAFTAR PUSTAKA}

Anonim, 2002, SNI 03-6861.1-2002, Spesifikasi Bahan Bangunan Bagian A (Bahan Bangunan Bukan Logam), Balitbang Departemen Kimpraswil, Jakarta.

Boen, Teddy, 2007, Bengkulu and West Sumatera Earthquakes September 122007 Structural Danage Report, Seminar dan Pameran HAKI 2007.
Murty, C, V, R, 2003, How Do Masonry Houses Behave During Earthquakes ?, Indian Institute of Technology Kanpur, Kanpur India.

Pusat Inovasi LIPI, Bata Tahan Gempa Geo 3 (brosur).

Widodo, 2007, Kerusakan Bangunan Pada Gempa Yogyakarta 27 Mei 2008 : Akibat Kebelumjelasan Code, Sosialisasi Atau Pelaksanaan? Seminar Dan Pameran HAKI 2007. 